\title{
Physical characterization and in vivo pharmacokinetic study of self-assembling amphotericin B-loaded lecithin-based mixed polymeric micelles
}

\author{
This article was published in the following Dove Press journal: \\ International Journal of Nanomedicine \\ 2 December 2015 \\ Number of times this article has been viewed
}

\author{
Ying-Chen Chen* \\ Chia-Yu Su* \\ Hua-Jun Jhan \\ Hsiu-O Ho \\ Ming-Thau Sheu \\ School of Pharmacy, College of \\ Pharmacy, Taipei Medical University, \\ Taipei, Taiwan \\ *These authors contributed equally \\ to this work
}

\begin{abstract}
To alleviate the inherent problems of amphotericin B (AmB), such as poor water solubility and nephrotoxicity, a novel self-assembling mixed polymeric micelle delivery system based on lecithin and combined with amphiphilic polymers, Pluronic ${ }^{\circledR}$, Kolliphor ${ }^{\circledR}$, d-alpha tocopheryl polyethylene glycol succinate, and 1,2-distearoyl-sn-glycero-3-phosphoethanolamine$N$-methoxy(poly(ethylene glycol)-2000 (DSPE-PEG2K) was developed. An optimal formulation (Ambicelles) composed of AmB:lecithin:DSPE-PEG2K in a 1:1:10 weight ratio was obtained. The particle size, polydispersion index, drug encapsulation efficiency, and drug loading were $187.20 \pm 10.55 \mathrm{~nm}, 0.51 \pm 0.017,90.14 \%$, and $7.51 \%$, respectively, and the solubility was increased from 0.001 to $5 \mathrm{mg} / \mathrm{mL}$. Compared with that of Fungizone ${ }^{\circledR}$, the bioavailability of Ambicelles administered intravenously and orally increased 2.18- and 1.50-fold, respectively. Regarding the in vitro cytotoxicity, Ambicelles had a higher cell viability than free AmB solution or Fungizone $^{\circledR}$ did. With pretreatment of $50 \mu \mathrm{g} / \mathrm{mL}$ ethanolic extract of Taiwanofungus camphoratus followed by AmB to HT2 29 colon cancer cells, the $50 \%$ inhibitory concentration of AmB solution was $12 \mu \mathrm{g} / \mathrm{mL}$, whereas that of Ambicelles was $1 \mu \mathrm{g} / \mathrm{mL}$, indicating that Ambicelles exerted a greater synergistic anticancer effect.
\end{abstract}

Keywords: amphotericin B, micelle, amphiphilic polymer, lecithin, DSPE-PEG

\section{Introduction}

Amphotericin B (AmB), ${ }^{1}$ a polyene antifungal agent that is commonly used to treat systemic fungal infections, ${ }^{2,3}$ is regarded as an anticancer adjuvant. ${ }^{4}$ Previously, it was reported that pretreated a Taiwanofungus camphoratus ethanolic extract (TCEE) and subsequent AmB application effectively induced apoptosis, inhibited HT29 cancer cell growth, and substantially diminished tumor size in vivo. It was assumed that TCEE contains sterols featuring ergostane or lanostane skeletons; therefore, pretreating cancer cells with TCEE might offer the insertion of ergostane or lanostane triterpenoids, and increase the susceptibility of AmB to cancer cells, leading to cell death. ${ }^{5}$

The poor water solubility and systemic toxicity of AmB have limited its clinical application in treating fungal infections and cancers. ${ }^{6,7}$ Fungizone ${ }^{\circledR}$ was first launched as a colloidal dispersion combined with sodium desoxycholate to form a micellar dispersion for encapsulating AmB. However, infusion toxicity and nephrotoxicity, likely related to the relative aggregation state of AmB, still frequently cause troublesome complications. ${ }^{3,8-10}$ Lipid-based formulations have been shown to encapsulate and disaggregate $\mathrm{AmB}$, shifting $\mathrm{AmB}$ distribution away from the kidneys, and a slow
Correspondence: Ming-Thau Sheu; Hsiu-O Ho

School of Pharmacy, College of Pharmacy, Taipei Medical University, $250 \mathrm{Wu}$-Hsing

Street, Taipei II0, Taiwan

Tel $+88622736|66|$ ext $6 \mid 12$

Fax +88622736 I66I ext 6112

Email mingsheu@tmu.edu.tw;

hsiuoho@tmu.edu.te 
release profile ensures that the drug remains a monomer form. ${ }^{11,12}$ Therefore, the following commercial products including a lipid complex (Abelcet $\left.{ }^{\circledR}\right)$ and a liposomal product (Ambisome ${ }^{\circledR}$ ) that encapsulate AmB with hydrogenated soybean lecithin, phosphatidylcholine, and cholesterol, have been marketed. The nephrotoxicity incidence of these lipid-based formulations is lower, and they are tolerated well when administered in higher doses. Nevertheless, their widespread use has been limited by high costs and high dose requirements. ${ }^{3}$ Thus, much effort has been expended to develop other cost-effective delivery systems (such as micelles, nanospheres, or conjugates) with lower toxicity.

Polymeric micelle-based drug delivery systems created from amphiphilic polymers, which self-assemble into structures with hydrophobic cores and hydrophilic shells, have been applied widely to deliver poorly soluble drugs. ${ }^{13,14}$ Hydrophobic drugs can be encapsulated in the core, and the hydrophilic portion affords the water solubility required for the system and prevents damage from reticuloendothelial systems, increasing bioavailability (BA). Moreover, the small size of micelles potentially increases the drug circulation time and facilitates favorable biodistribution. ${ }^{15-18}$ Krishnadas et al ${ }^{19}$ prepared a paclitaxel micelle system by using 1,2-distearoyl-sn-glycero-3-phosphoethanolamine- $N$ methoxy(poly(ethylene glycol)-2000 (DSPE-PEG2K) only or DSPE-PEG2K and egg-phosphatidylcholine, concluding that the DSPE-PEG2K and egg-phosphatidylcholine mixed polymeric micelle exhibited greater solubilization than did the DSPE-PEG2K single polymeric micelle, while retaining its beneficial characteristics. Krishnadas et al ${ }^{19}$ speculated that inserting a small percentage of this lipid into a micellar system composed of an amphiphilic micelle can increase the volume of the hydrophobic region of the micelle, thereby creating more space in which the hydrophobic drug can be solubilized. Mixed polymeric micelles feature synergistic properties, such as increased drug stability and drug loading efficiency, which are superior to those of individual polymeric micelles. ${ }^{20}$ Wei et $\mathrm{al}^{21}$ developed a Pluronic ${ }^{\circledR}$ P123 and F127 mixed micellar system for use with paclitaxel, and the $50 \%$ inhibitory concentration $\left(\mathrm{IC}_{50}\right)$ of micelles against human lung adenocarcinoma A-549 cells was lower than that of Taxol ${ }^{\circledR}$ injection and free paclitaxel. Zhao et $\mathrm{al}^{22}$ prepared mixed polymeric micelles for use with quercetin combined with Pluronic $^{\circledR}$ P123 and d-alpha tocopheryl polyethylene glycol succinate (TPGS); consequentially, the solubility of the quercetin radically increased to $5.56 \mathrm{mg} / \mathrm{mL}$ (a 2738-fold increase compared with free quercetin). Doxorubicin-loaded mixed micelles composed of Pluronic ${ }^{\circledR}$ L61 and F127 have been evaluated in a Phase II study involving patients with advanced esophageal carcinoma. ${ }^{23}$

Numerous studies have reported that AmB is poorly absorbed by the gastrointestinal (GI) tract; ${ }^{24-27}$ however, when AmB was incorporated into mixed micelles containing bile acids and phospholipids, the intestinal permeability and subsequent GI absorption increased. ${ }^{25}$ Vakil and Kwon ${ }^{28}$ used DSPE-PEG micelles to deliver AmB, and the micelles incorporated deaggregated AmB. Lecithin, a natural lipid mixture of phospholipids, is frequently used to prepare various drug delivery systems, such as microemulsions, liposomes, micelles, and nanoparticles, and is considered to be a safe and biocompatible excipient. Phospholipids, which are critical components of the cell membrane, can maintain cell membrane fluidity and enable drugs to be easily absorbed. ${ }^{20}$ Therefore, lecithin-based nanoparticles are frequently prepared to increase the BA of drugs. Tan et $\mathrm{al}^{29}$ developed chitosan-lecithin nanoparticles for administrating quercetin topically; the nanoparticles notably enhanced skin permeation and promoted quercetin retention in the epidermis compared with a quercetin propylene glycol solution. Li et $\mathrm{al}^{30}$ prepared lecithin-containing nanoparticles for quercetin, and in vivo pharmacokinetic $(\mathrm{PK})$ studies revealed that the nanoparticles had a higher relative BA (more than five-fold) compared with the quercetin suspension. Lecithin improved the therapeutic efficacy of drugs with poor oral absorption and poor water solubility. ${ }^{31}$ Therefore, the objective of the current study was to develop a novel self-assembling mixed polymeric micellar system for AmB that features greater solubility and less toxicity. AmB-loaded mixed polymeric micelles were prepared by mixing lecithin and various amphiphilic polymers (TPGS, DSPE-PEG, Pluronic ${ }^{\circledR}$, and Kolliphor ${ }^{\circledR}$ ) by using a thin-film method. The optimal preparation was characterized according to physicochemical properties (particle size, morphological observation, drug loading, entrapment efficacy, and stability), in vitro cytotoxicity, and in vivo PKs.

\section{Materials and methods Chemicals and reagents}

AmB was purchased from Synbiotics Limited (Gujarat, India), and Fungizone ${ }^{\circledR}$ was obtained from Bristol-Myers Squibb (Rueil-Malmaison, France). T. camphoratus was provided by Well Shine Biotechnology Development Co., Ltd. (Lot: WS201001SC, Taipei, Taiwan), and lecithin (alpha granule) was procured from Acros Organics (Thermo Fisher Scientific, Waltham, MA, USA). Pluronic ${ }^{\circledR}$ series F87, F127, and F68; TPGS; and Kolliphor ${ }^{\circledR}$ were purchased from BASF (Hanover, Germany). Pluronic ${ }^{\circledR}$ L121, F108, 
and P123; acetonitrile; methanol; dimethyl sulfoxide; and sodium acetate were obtained from Sigma-Aldrich (St Louis MO, USA). DSPE-PEG2K was procured from NOF (Tokyo, Japan), and heparin 5,000 IU/mL was purchased from China Chemical \& Pharmaceutical Co., Ltd. (Hsinchu, Taiwan). Fetal bovine serum (FBS) and glutamine were purchased from Biowest (Nuaillé, France). All reagents used for high performance liquid chromatography (HPLC) analysis, including acetonitrile and formic acid, were HPLC grade, and other reagents were analytical grade.

\section{Preparation of self-assembling AmB- loaded lecithin-based mixed polymeric micelles}

Since lecithin is preferably soluble in dichloromethane or chloroform and AmB is preferably soluble in methanol, solvent mixtures of methanol-dichloromethane or methanol-chloroform in two ratios of 9:1 and 19:1 were compared to determine the effect on the mean particle size and size distribution of micelles. The 19:1 ratio of methanol-dichloromethane and methanol-chloroform was optimal for preparing the thin films and was used in the following experiments. The AmB-loaded lecithin-based mixed polymeric micelles were prepared using a thin film method, as described in Zhang et al. ${ }^{32}$ Figure 1 shows the preparation scheme. Briefly, AmB and lecithin were dissolved separately in methanol and dichloromethane and mixed according to a predetermined ratio. Different ratios of various polymers (Pluronic ${ }^{\circledR}$ grades of F87, F127, F68, L121, F108, and P123; TPGS; Kolliphor ${ }^{\circledR}$ RH40 and ELP; and DSPE-PEG2K) were then added and mixed in a roundbottomed flask. The mixture was subsequently evaporated using a rotary evaporator at $50^{\circ} \mathrm{C}$ under reduced pressure to obtain a thin film. To remove the residual solvent, the thin film was maintained in a vacuum overnight at room temperature. Self-assembly of the thin films resulting in micelle formation was examined by adding $1 \mathrm{~mL}$ of deionized water and shaking the micelle solution gently until the thin film was completely dispersed. The unincorporated AmB aggregates were removed by passing the solution through a $0.22 \mu \mathrm{m}$ filter (Millipore, MA, USA). Self-assembling AmB-loaded mixed polymeric micelles in the filtrate were evaluated to determine characteristics such as the average particle size and size distribution, encapsulation efficiency, and drug loading.

\section{Characterization of self-assembling AmB-loaded mixed polymeric micelles}

The mean particle size and size distribution of AmB-loaded mixed polymeric micelles were measured using an N5 submicron particle size analyzer (Beckman Coulter, CA, USA) at room temperature. All measurements were performed in triplicate. The morphology was observed using transmission electron microscopy (TEM; Hitachi H-700, Hitachi Ltd., Tokyo, Japan).

\section{Quantification of AmB in AmB-loaded mixed polymeric micelles}

The encapsulated amount of AmB in mixed polymeric micelles was determined through HPLC, the analysis method of which was modified from that by Italia et al. ${ }^{33}$ First, the micelles were solubilized in methanol. AmB was analyzed using a $\mathrm{C} 18$ reversed phase column $(250 \times 4.6 \mathrm{~mm}$, $5 \mu \mathrm{m}$; BIOSIL, Taipei, Taiwan) in a Waters Alliance e2695 HPLC system and detected using a Waters 2489 ultraviolet (UV)/Visible detector (Waters Corporation, MA, USA). A gradient method in which the mobile phase A consisted of $2 \mathrm{mM}$ acetate buffer ( $\mathrm{pH} 4.0)$ and mobile phase B consisted of acetonitrile was used. The flow rate was $1.0 \mathrm{~mL} / \mathrm{min}$, the detection wavelength was set at $407 \mathrm{~nm}$, and the temperature was $40^{\circ} \mathrm{C}$. When the $\mathrm{AmB}$ concentration was evident from the calibration curve, the encapsulation efficiency percentage $(\mathrm{EE} \%)$ and drug loading percentage (DL\%) were calculated according to Equations 1 and 2, respectively:

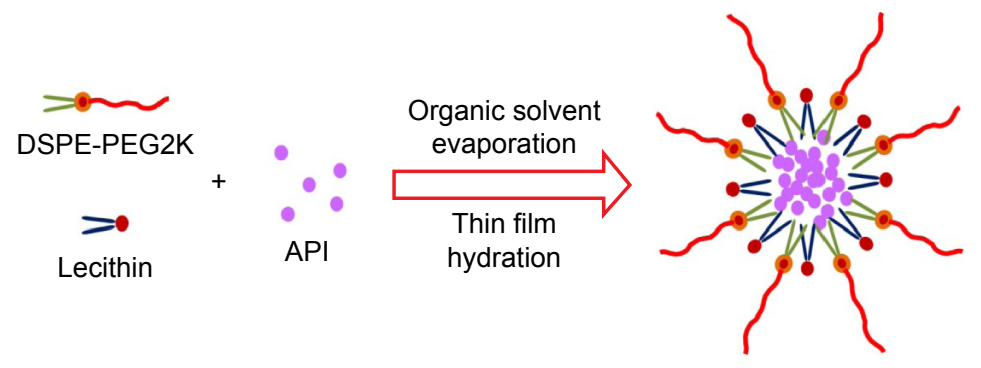

Figure I Scheme for preparing amphotericin B-loaded mixed polymeric micelles.

Abbreviations: DSPE-PEG2K, I,2-distearoyl-sn-glycero-3-phosphoethanolamine-N-methoxy(poly(ethylene glycol)-2000; API, active pharmaceutical ingredients. 


$$
\begin{gathered}
\mathrm{EE} \%=\mathrm{W}_{\mathrm{M}} / \mathrm{W}_{\mathrm{I}} \times 100 \\
\mathrm{DL} \%=\mathrm{W}_{\mathrm{M}} /\left(\mathrm{W}_{\mathrm{P}}+\mathrm{W}_{\mathrm{M}}\right) \times 100
\end{gathered}
$$

where $\mathrm{W}_{\mathrm{M}}$ is the weight of the drugs in the micelles, $\mathrm{W}_{\mathrm{I}}$ is the weight of the initial feeding drug, and $\mathrm{W}_{\mathrm{P}}$ is the weight of the initial feeding polymers.

\section{Stability}

The optimal formulation was selected based on the above evaluations and named Ambicelles (composed of AmB:lecithin:DSPE-PEG2K). Ambicelles was placed in simulated gastric fluid (SGF) without pepsin $(0.1 \mathrm{M} \mathrm{HCl}$ solution, $\mathrm{pH}$ 1.2) and simulated intestinal fluid (SIF, $\mathrm{pH}$ 6.8) to evaluate the stability in a GI tract fluid simulation. The compositions of the SGF and SIF were based on United States Pharmacopeia XXIX. After 2 hours, the particle size and concentration of $\mathrm{AmB}$ were measured.

\section{In vivo PK studies of intravenous and oral administration}

The protocol of this study was approved by the Institutional Animal Care and Use Committee (IACUC) of Taipei Medical University (number LAC-101-0277) and all experiments were performed under the approved animal care guidelines. Male Sprague Dawley rats aged 8-10 weeks were used to investigate the PK profile of Ambicelles and Fungizone ${ }^{\circledR}$. The rats were injected with a single $0.8 \mathrm{mg} / \mathrm{kg}$ dose of Ambicelles or Fungizone ${ }^{\circledR}$ through tail vein injection (three rats per group). Blood samples were collected in heparinized tubes from the jugular vein $0.083,0.166,0.25,0.5,1,2,4,7,12$, 24,48 , and 72 hours after administration.

In addition, the rats were randomly assigned to two groups and orally administered a single $10 \mathrm{mg} / \mathrm{kg}$ dose of Ambicelles or Fungizone $^{\circledR}$ (three rats per group). Blood samples were collected in heparinized tubes from the jugular vein 1, 2, 3, 4, 5, $6,8,10,12,24,36$, and 48 hours after oral administration. All blood samples were immediately centrifuged at $3,000 \times \mathrm{g}$ for 15 minutes to obtain plasma, which was stored at $-30^{\circ} \mathrm{C}$ before HPLC analysis. PK parameters were calculated for each group by using the mean and standard deviation from individual rats and estimated using noncompartmental analysis. The maximum plasma concentration $\left(\mathrm{C}_{\max }\right)$ and the time to reach $\mathrm{C}_{\text {max }}\left(\mathrm{T}_{\max }\right)$ were directly obtained from the observed concentration-time curve data. The terminal elimination rate constant $\left(\mathrm{K}_{\mathrm{e}}\right)$ was estimated according to the slope of the $\log$-linear phase of declining plasma concentration evident in the $\mathrm{AmB}$ versus time graph. The half-life $\left(\mathrm{T}_{1 / 2}\right)$ was calculated using the following equation: $T_{1 / 2}=\ln 2 / \mathrm{K}_{\mathrm{e}}$. The area under the concentration time curve $\left(\mathrm{AUC}_{0 \rightarrow \text { last }}\right)$ was calculated using the trapezoidal method. Summing the $\mathrm{AUC}_{0 \rightarrow \text { last }}$ and the concentration at the last measured point divided by $\mathrm{K}_{\mathrm{e}}$ yielded $\mathrm{AUC}_{0 \rightarrow \infty}$. Clearance $(\mathrm{CL})$ was calculated by dividing the dose by $\mathrm{AUC}_{0 \rightarrow \infty}$, and the volume of distribution (V) was obtained by dividing CL by $\mathrm{K}_{\mathrm{e}}$.

\section{Cell viability assays}

The cytotoxicity of Ambicelles, free AmB solution, and Fungizone $^{\circledR}$ to HT29 colon cancer cells was evaluated using an MTT assay. HT29 cells were cultured with Roswell Park Memorial Institute-1640, 10\% FBS, 10\% L-glutamine, and 10\% penicillin-streptomycin. Cells were seeded in a density of $5 \times 10^{4}$ per well in 24-well plates. After 24 hours of treatment at $37^{\circ} \mathrm{C}$ with $5 \% \mathrm{CO}_{2}$, cell survival was measured using a tetrazolium salt MTT assay. One hundred microliters of MTT $(6 \mathrm{mg} / \mathrm{mL})$ was added to each well and incubated for 3 hours. The medium was then removed, and $200 \mu \mathrm{L}$ of dimethyl sulfoxide was added to dissolve any purple formazan crystal formations. Cell viability was measured using a spectrophotometer; the absorbance was set at $520 \mathrm{~nm}$ (Bio-Tek, Winooski, VT, USA).

In addition, the anticancer effect of $\mathrm{AmB}$ pretreated with TCEE was evaluated. The HT29 colon cancer cells were seeded in a density of $5 \times 10^{4}$ per well in 24 -well plates and incubated for 24 hours; the medium was replaced with $500 \mu \mathrm{L}$ of a medium containing various concentrations of TCEE. After 24 hours of incubation, the medium was replaced with a new medium containing Ambicelles, a free AmB solution, or Fungizone ${ }^{\circledR}$. After a further 24 hours of treatment, cell viability was determined using an MTT assay.

\section{Statistical analysis}

Statistical analysis of all results was performed using the Student's $t$-test in which unequal variance was assumed. A two-tailed $P$-value lower than 0.05 indicated a statistically significant difference. Tabulated data are presented as the mean \pm standard deviation.

\section{Results}

\section{Preparation and characterization of AmB-loaded lecithin-based mixed polymeric micelles}

Because drug safety and a smaller particle size were considered, the mixture of methanol-dichloromethane in a 19:1 ratio was used to dissolve the $\mathrm{AmB}$ and lecithin and prepare AmB-loaded lecithin-based mixed polymeric micelles with additional amphiphilic polymers. The major factors influencing the particle size, DL\%, and EE\% of the mixed polymeric micelles are the types of polymers and the proportions of 
Table I Particle size and visual appearance (precipitation or clear) after 24 hours for formulations containing different polymers

\begin{tabular}{|c|c|c|}
\hline $\begin{array}{l}\text { Polymer used in } \\
\text { formulation }(1: 1: 20)\end{array}$ & $\begin{array}{l}\text { Mean size }(\mathrm{nm}) \\
\text { mean } \pm \text { SD }(\mathrm{PDI})\end{array}$ & $\begin{array}{l}\text { Visual observation } \\
\text { after } 24 \text { hours }\end{array}$ \\
\hline TPGS & $\begin{array}{l}842.8 \pm 29.31 \\
(0.226 \pm 0.215)\end{array}$ & Precipitation \\
\hline Kolliphor RH40 & $\begin{array}{l}769.4 \pm 41.90 \\
(0.413 \pm 0.258)\end{array}$ & Precipitation \\
\hline Kolliphor ELP & $\begin{array}{l}1,782.1 \pm 343.80 \\
(1.597 \pm 0.340)\end{array}$ & Precipitation \\
\hline Pluronic LI2I & $\begin{array}{l}I, 101.2 \pm 61.95 \\
(0.722 \pm 0.573)\end{array}$ & Precipitation \\
\hline Pluronic PI23 & $\begin{array}{l}607.5 \pm 18.95 \\
(0.246 \pm 0.136)\end{array}$ & Precipitation \\
\hline Pluronic FI 27 & $\begin{array}{l}I, 051.8 \pm 66.74 \\
(0.7 \mid I \pm 0.109)\end{array}$ & Precipitation \\
\hline Pluronic F87 & $\begin{array}{l}719.7 \pm 24.21 \\
(0.599 \pm 0.121)\end{array}$ & Precipitation \\
\hline Pluronic F68 & $\begin{array}{l}1,560.1 \pm 182.28 \\
(0.623 \pm 0.132)\end{array}$ & Precipitation \\
\hline Pluronic FI08 & $\begin{array}{l}I, 117.2 \pm 7.15 \\
(0.554 \pm 0.315)\end{array}$ & Precipitation \\
\hline DSPE-PEG2K & $\begin{array}{l}\mid 49.5 \pm 0.40 \\
(0.605 \pm 0.033)\end{array}$ & Clear \\
\hline
\end{tabular}

Note: Ratio of polymers in the micelle formula, amphotericin B:lecithin:polymer =I:1:20. Abbreviations: PDI, polydispersion index; TPGS, d-alpha tocopheryl polyethylene glycol succinate; DSPE-PEG2K, I,2-distearoyl-sn-glycero-3-phosphoethanolamine$\mathrm{N}$-methoxy(poly(ethylene glycol)-2000; SD, standard deviation.

drug and polymers; thus, various polymers (TPGS, DSPEPEG, Pluronic ${ }^{\circledR}$ series, and Kolliphor ${ }^{\circledR}$ ) and different ratios of AmB, lecithin, and polymers were investigated. To select a suitable polymer for the self-assembling mixed polymeric micelles, the proportion of the formulations was fixed as AmB:lecithin:polymer $=1: 1: 20$, and the effect of different polymers was assessed. Table 1 lists the particle size, polydispersion index, and visual appearance (precipitation or clear) of each formulation after 24 hours.

In the formulations including the Pluronic ${ }^{\circledR}$ series, the particle sizes exceeded $200 \mathrm{~nm}$; the EE\% was lower than $50 \%$; and micelles precipitated after 24 hours regardless of the ratios. Particles smaller than $200 \mathrm{~nm}$ facilitate extensive circulation of drugs in the blood and drug targeting. ${ }^{34}$ Except for the particle size in the DSPE-PEG2K formulation, the particle sizes in the formulations with other polymers exceeded $200 \mathrm{~nm}$, and the micelles precipitated after 24 hours; therefore, we used the DSPE-PEG2K as the polymer to be further optimized. Table 2 lists the particle size, $\mathrm{EE} \%$, and $\mathrm{DL} \%$ for formulations with various ratios of DSPE-PEG2K. The results revealed that the particle sizes were $\sim 200 \mathrm{~nm}$ or smaller. LD1-10 was selected as the optimal formulation because LD1-5 precipitated in 2 days. Although LD1-20 had the smallest particle size and highest $\mathrm{EE} \%$, using the highest amount of DSPE-PEG2K resulted in a low DL\%. In this study, the optimal formulation was AmB:lecithin:DSPE-PEG2K =1:1:10 (weight ratio) and was named Ambicelles. In addition, we evaluated the effect of lecithin on particle size (Table 2); in the LD0-5 and LD1-5 formulations, adding lecithin reduced the particle size from $283.23 \pm 45.47$ to $221.28 \pm 9.08 \mathrm{~nm}$, and the reduction was also seen in LD0-10 and LD1-10, and the particle size decreased from $320.43 \pm 10.03$ to $187.20 \pm 10.55 \mathrm{~nm}$. However, adding more lecithin (LD2-10) caused a decrease in EE\%.

\section{Transmission electron micrographs}

The morphology of Ambicelles and Fungizone ${ }^{\circledR}$ was observed using TEM imaging. The TEM images depicted in Figure 2

Table 2 Particle size, polydispersity index, entrapment efficacy, and drug loading for formulations with various DSPE-PEG2K ratios

\begin{tabular}{|c|c|c|c|c|}
\hline Name & $\begin{array}{l}\text { AmB:lecithin: } \\
\text { DSPE-PEG2K }\end{array}$ & $\begin{array}{l}\text { Mean size }(\mathrm{nm}) \\
\text { mean } \pm \mathrm{SD}(\mathrm{PDI})\end{array}$ & $\begin{array}{l}\text { Entrapment } \\
\text { efficacy (\%) }\end{array}$ & $\begin{array}{l}\text { Drug } \\
\text { loading (\%) }\end{array}$ \\
\hline LD0-5 & I:0:5 & $\begin{array}{l}283.23 \pm 45.47 \\
(0.68 \pm 0.048)\end{array}$ & 94.95 & 15.83 \\
\hline LDI-5 & I:1:5 & $\begin{array}{l}221.28 \pm 9.08 \\
(0.70 \pm 0.053)\end{array}$ & 83.98 & 12.00 \\
\hline LD2-5 & $1: 2: 5$ & $\begin{array}{l}222.40 \pm 7.18 \\
(0.67 \pm 0.072)\end{array}$ & 44.7I & 5.59 \\
\hline LD0-10 & I:0:10 & $\begin{array}{l}320.43 \pm 10.03 \\
(0.91 \pm 0.054)\end{array}$ & 96.67 & 8.79 \\
\hline LDI-10 & I:I:I0 & $\begin{array}{l}187.20 \pm 10.55 \\
(0.5 \mid \pm 0.017)\end{array}$ & 90.14 & 7.51 \\
\hline LDI-20 & I:I:20 & $\begin{array}{l}149.50 \pm 0.40 \\
(0.605 \pm 0.033)\end{array}$ & 92.17 & 4.19 \\
\hline LD2-10 & $\mathrm{I}: 2: 10$ & $\begin{array}{l}200.80 \pm 6.80 \\
(0.84 \pm 0.088)\end{array}$ & 66.17 & 5.09 \\
\hline
\end{tabular}

Abbreviations: DSPE-PEG2K, I,2-distearoyl-sn-glycero-3-phosphoethanolamine-N-methoxy(poly(ethylene glycol)-2000; AmB, amphotericin B; PDI, polydispersion index; $\mathrm{SD}$, standard deviation. 

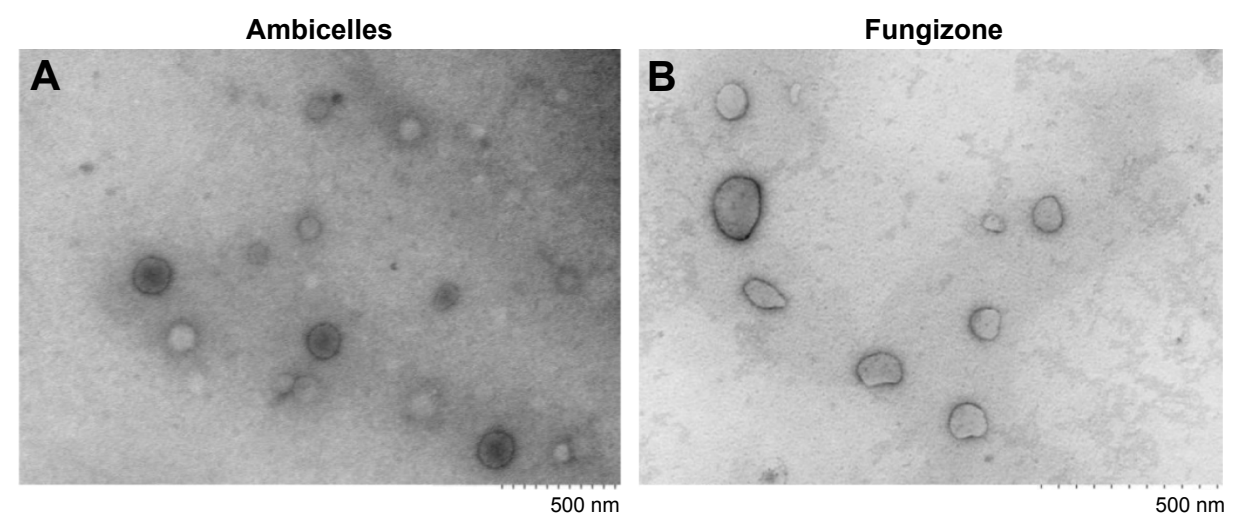

Figure 2 Transmission electron micrographs of $(\mathbf{A})$ Ambicelles and (B) Fungizone ${ }^{\circledR}$.

reveal that both Ambicelles and Fungizone ${ }^{\circledR}$ were spherical and uniform and had mean particle sizes of $\sim 200 \mathrm{~nm}$.

\section{Stability of AmB micelles in SGF and SIF}

To evaluate the feasibility of Ambicelles for oral use, Ambicelles was placed in SGF and SIF for 2 hours. The particle size of the Ambicelles remained smaller than $200 \mathrm{~nm}$, and the EE\% exceeded 90\%. The results indicated that Ambicelles was stable in SGF and SIF, and no degradation occurred in the GI fluid.

\section{PK studies of AmB micelles}

Figure 3 shows a curve of the plasma concentration of $A m B$ versus time for the Sprague Dawley rats after they intravenously received $0.8 \mathrm{mg} / \mathrm{kg}$ Fungizone ${ }^{\circledR}$ and Ambicelles. Table 3 shows the PK parameters. The $\mathrm{AUC}_{0 \rightarrow \infty}$ value of Ambicelles was 2.18 times higher than that for Fungizone ${ }^{\circledR}$,

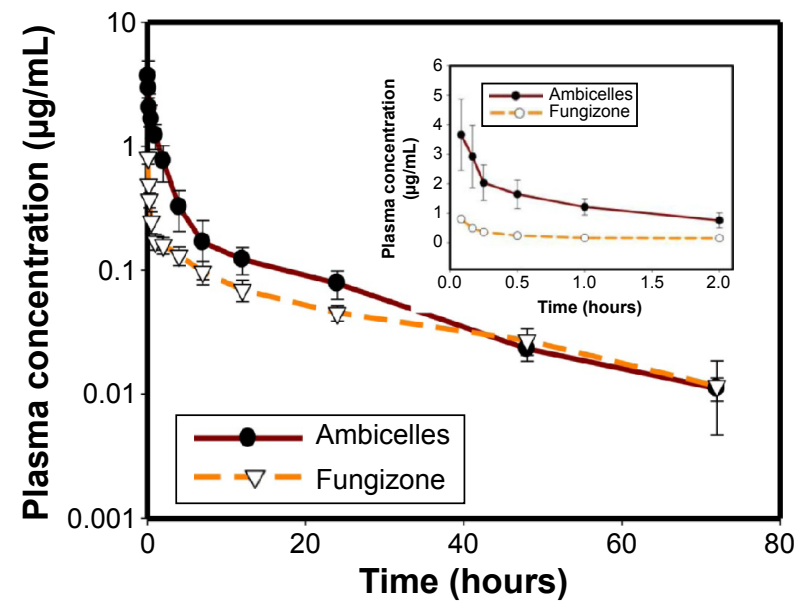

Figure 3 Plasma concentration-time curves of amphotericin B after intravenous administration of Fungizone ${ }^{\circledR}$ or Ambicelles $(0.8 \mathrm{mg} / \mathrm{kg})$ to rats.

Note: Each data point represents the mean \pm standard deviation of three determinations $(n=3)$. Inset shows plasma concentration time profile from time 0 to 2 hours. whereas the values of $\mathrm{V}$ and $\mathrm{CL}$ were lower. Figure 4 shows a curve of the plasma concentration of $\mathrm{AmB}$ versus time for rats administered a single $10 \mathrm{mg} / \mathrm{kg}$ oral dose of Fungizone $^{\circledR}$ and Ambicelles solutions. The PK parameters of the formulations administered orally are shown in Table 3. The time at which the maximal plasma concentration $\left(\mathrm{T}_{\max }\right)$ occurred in Ambicelles was earlier than that in Fungizone ${ }^{\mathbb{B}}$, and Ambicelles had a higher value of $\mathrm{C}_{\max }$. The absolute BA values of Ambicelles and Fungizone ${ }^{\circledR}$ were $3.13 \%$ and $2.08 \%$, respectively.

\section{In vitro cytotoxicity of different AmB formulations to HT29 cells}

Three types of formulation, namely, AmB (a free AmB solution), Fungizone ${ }^{\circledR}$, and Ambicelles in different concentrations, were fed to HT29 cells to determine cell viability. Figure 5 shows that cell viability was higher when the cells were treated with Ambicelles than when they were treated with the other formulations.

\section{The synergistic anticancer effect of TCEE and different AmB formulations on HT29 cells}

HT29 cells were pretreated with $50 \mu \mathrm{g} / \mathrm{mL}$ of TCEE before they were treated with a free AmB solution, Fungizone ${ }^{\circledR}$, or Ambicelles; Figure 6 depicts the cell viability results. The $\mathrm{IC}_{50}$ values of Fungizone ${ }^{\circledR}$ and the free AmB solution were $>50$ and $12.5 \mu \mathrm{g} / \mathrm{mL}$, respectively; by contrast, Ambicelles exhibited a lower $\mathrm{IC}_{50}$ value of $1 \mu \mathrm{g} / \mathrm{mL}$.

\section{Discussion}

Self-assembling mixed polymeric micelles can solubilize a wide range of molecules with poor water solubility and act as a safe carrier for drug delivery without the use of potentially 
Table 3 Summary of pharmacokinetic parameters of amphotericin B after intravenous (IV) or oral administration of Fungizone ${ }^{\circledR}$ and Ambicelles $(n=3)$

\begin{tabular}{|c|c|c|c|c|}
\hline Parameters & Fungizone ${ }^{\circledR}$ IV & Ambicelles IV & Fungizone ${ }^{\circledR}$ oral & Ambicelles oral \\
\hline Dose $(\mathrm{mg} / \mathrm{kg})$ & 0.8 & 0.8 & 10 & 10 \\
\hline $\mathrm{AUC}_{0-24}(\mathrm{~h} \cdot \mu \mathrm{g} / \mathrm{mL})$ & $2.222 \pm 0.318$ & $6.746 \pm 2.061$ & $0.937 \pm 0.092$ & $0.979 \pm 0.080$ \\
\hline $\mathrm{AUC}_{0-72}(\mathrm{~h} \cdot \mu \mathrm{g} / \mathrm{mL})$ & $3.556 \pm 0.393$ & $8.370 \pm 2.216$ & & \\
\hline $\mathrm{AUC}_{0 \rightarrow \infty}(\mathrm{h} \cdot \mu \mathrm{g} / \mathrm{mL})$ & $3.962 \pm 0.320$ & $8.642 \pm 3.258$ & $1.02 I \pm 0.148$ & $1.555 \pm 0.150$ \\
\hline $\mathrm{C}_{\max }(\mu g / \mathrm{mL})$ & NA & NA & $0.066 \pm 0.013$ & $0.074 \pm 0.009$ \\
\hline $\mathrm{T}_{\max }(\mathrm{h})$ & NA & NA & $7.00 \pm 2.65$ & $3.00 \pm 1.73$ \\
\hline $\mathrm{T}_{1 / 2}(\mathrm{~h})$ & $17.54 \pm 1.15$ & $16.4 \mid \pm 2.28$ & $5.996 \pm 0.50$ & $13.93 \pm 3.0 \mid$ \\
\hline $\mathrm{CL}(\mathrm{mL} / \mathrm{h} / \mathrm{kg})$ & $0.202 \pm 0.018$ & $0.092 \pm 0.038$ & $9.790 \pm 1.350$ & $6.910 \pm 0.660$ \\
\hline$V(\mathrm{~mL} / \mathrm{kg})$ & $7.03 \pm 2.72$ & $2.19 \pm 1.22$ & $84.70 \pm 18.87$ & $138.94 \pm 32.97$ \\
\hline BA (\%) (IV-oral) & 100 & NA & 2.08 & 3.13 \\
\hline BA (\%) (IV-IV) & 100 & 218 & NA & NA \\
\hline
\end{tabular}

Note: Data shown as mean \pm standard deviation unless otherwise stated.

Abbreviations: AUC, area under the concentration time curve; $\mathrm{C}_{\max }$, maximal plasma concentration; $\mathrm{T}_{1 / 2}$, half-life; $\mathrm{CL}$, clearance; $\mathrm{V}$, volume of distribution; $\mathrm{NA}$, not applicable; BA, bioavailability.

harmful surfactants and excipients. In addition, particle size directly affects the biodistribution and circulation time of micelles in vivo, and the small particle size $(<200 \mathrm{~nm})$ of micelles can reduce uptake by the reticuloendothelial system and enable efficient passive tumor-targeting ability through enhanced permeability and retention effects. ${ }^{35}$ Therefore, the goal of the study was to prepare self-assembling lecithinbased mixed polymeric micelles for AmB.

Lecithin alone formed a lipid complex with AmB; however, the particle size was $1,624.5 \pm 384.85 \mathrm{~nm}$ (data not shown), because the hydrophilic component of the lecithin was too short and the surface tension was too high to form stable micelles. Therefore, we added amphiphilic polymers (TPGS, DSPE-PEG, Pluronic ${ }^{\circledR}$, and Kolliphor ${ }^{\circledR}$ ), which reduced the surface tension, had amphiphilic characteristics in an aqueous environment, and self-assembled to form stable micelles..$^{23,36-38}$ The hydrophilic blocks of amphiphilic

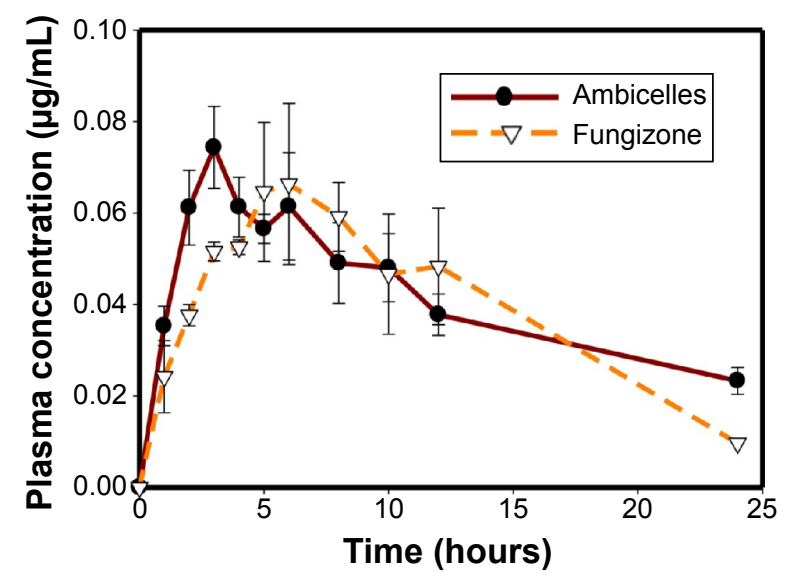

Figure 4 Plasma concentration-time curves of amphotericin B after oral administration of Fungizone ${ }^{\circledR}$ or Ambicelles $(10 \mathrm{mg} / \mathrm{kg}$ ) to rats.

Note: Each data point represents the mean \pm standard deviation of three determinations $(n=3)$. polymers formed an outer shell, and the hydrophobic blocks constitute the core of the micelle, which acts as the drugcontaining site.

Previous studies have reported that AmB micelles prepared using the thin film method were nonhemolytic at $15 \mathrm{mg} / \mathrm{mL}$, whereas those prepared using the dialysis method caused $50 \%$ hemolysis at $3.8 \mathrm{mg} / \mathrm{mL}$, and AmB caused $100 \%$ hemolysis at $1.0 \mathrm{mg} / \mathrm{mL}$. Through the thin film method, the toxicity of hemolysis can be effectively reduced. ${ }^{34}$ Therefore, we employed the thin film method to prepare mixed polymeric micelles for $\mathrm{AmB}$ and used an effective solvent (methanol-dichloromethane =19:1) to dissolve AmB, lecithin, and the polymer.

Pluronic $^{\circledR}$ contains hydrophilic poly(ethylene oxidep) (PEO) blocks and hydrophobic poly(propylene oxide) (PPO) blocks arranged in a triblock structure: PEO-PPO-PEO. The length of the PPO and PEO results in various types

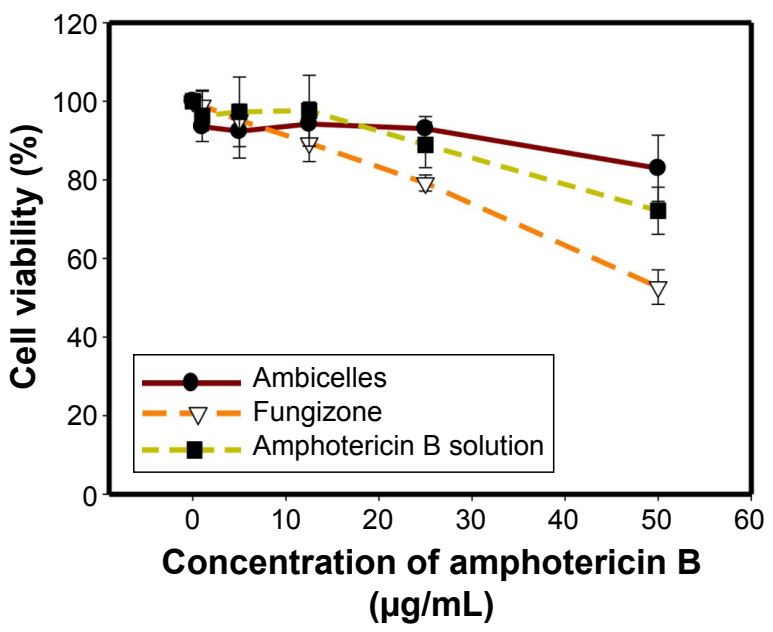

Figure 5 Viability of HT29 cells after treatment with various concentrations of amphotericin B, Fungizone ${ }^{\circledR}$, or Ambicelles. 


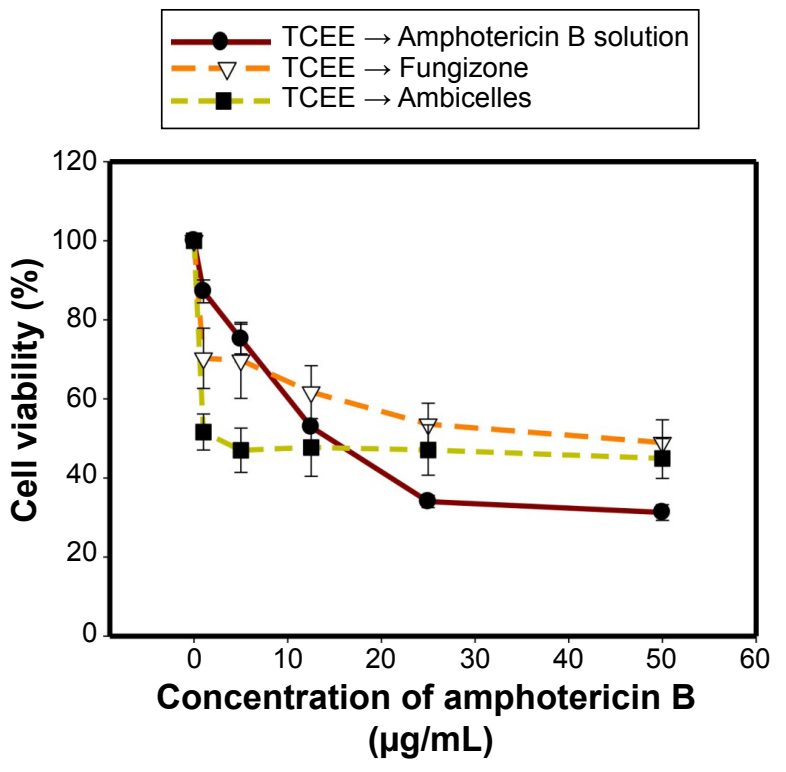

Figure 6 Viability of HT29 cells after pretreatment with $50 \mu \mathrm{g} / \mathrm{mL}$ of Taiwanofungus camphoratus ethanolic extract (TCEE), followed by treatment with various concentrations of an amphotericin B, Fungizone ${ }^{\circledR}$, or Ambicelles.

of Pluronic ${ }^{\circledR}$ and influences micelle formation; thus, various types of Pluronic ${ }^{\circledR}$ were evaluated in this study. When Pluronic $^{\circledR}$, lecithin, and AmB were combined, the hydrophobic segments of Pluronic ${ }^{\circledR}$ were inserted into the core formed by lecithin and AmB, and the hydrophilic segments extended to the aqueous phase. Because the hydrophilic group of the Pluronic $^{\circledR}$ was at the end and the hydrophobic group was in the middle, the structure of the Pluronic ${ }^{\circledR}$ became U shaped; the hydrophobic part inserted in the core and hydrophilic part extended outwardly. However, the chemical structure of AmB is more stereoscopic, and the U-shaped structure of Pluronic ${ }^{\circledR}$ may hinder encapsulating the AmB. The results reveal that the Pluronic ${ }^{\circledR}$ series used in this study (Pluronic ${ }^{\circledR}$ F87, F127, F68, L121, F108, and P123) were unsuitable polymers for loading $\mathrm{AmB}$ in lecithin-based mixed polymeric micelles.

PEG has been used widely because of its high hydrophilic ability and varied conformational flexibility. The inner hydrophobic block has exhibited substantial variability, and phospholipids such as DSPE (DSPE-PEG2K) have been investigated extensively because of their biocompatibility, stability, and regulatory approval in the US and Europe. ${ }^{39,40}$ For example, Remsberg et $\mathrm{al}^{39}$ loaded ridaforolimus into DSPE-PEG2K micelles, thereby improving the aqueous solubility of the ridaforolimus from $200 \mu \mathrm{g} / \mathrm{mL}$ to $8.9 \mathrm{mg} / \mathrm{mL}$ (an $\sim 40$-fold increase). Moreover, Doxil ${ }^{\circledR}$ (doxorubicin liposome), which has been approved for clinical application, includes DSPE-PEG2K, enhances liposome stability, and prolongs blood circulation time. An outer coat of PEG imparts "stealth" characteristics, allowing the PEG-derived micelles to circulate for long periods of time, accumulate at the tumor site according to the enhanced permeability and retention effect, and avoid the mononuclear phagocyte system. Therefore, encapsulating a drug in a PEG-derived micelle may reduce nonspecific systemic toxicity. ${ }^{41-44}$

In DSPE-PEG2K formulations, the micelle size decreased and the EE\% increased as the amount of DSPE-PEG2K was increased. This result indicates that the micelle size decreased as the polymer-drug ratio increased. When the initial drug feeding amount was increased, the DL\% increased, but the EE\% decreased. Studies have reported that the stability of polymeric micellar systems decreases as the DL\% increases, because the hydrophilic-hydrophobic balance is crucial for micelle stability, but may be lost when hydrophobic drugs are introduced. The physical stability of drug-loaded polymeric micelles is problematic when they are conserved for a long period of time; thus, the drug-polymer ratio is critical. Vakil and $\mathrm{Kwon}^{28}$ used DSPE-PEG2K micelles to deliver AmB; the solubility was $0.32 \pm 0.01$ and $0.39 \pm 0.01 \mathrm{mg} / \mathrm{mL}$ when the ratio of DSPE-PEG2K:AmB (w/w) was 2.81 and 16.81 , respectively. The micelles could incorporate and deaggregate $\mathrm{AmB}$ and, thus, exerted less hemolytic activity than did free AmB. In the current study, the optimal formulation, Ambicelles, included AmB:lecithin:DSPE-PEG2K =1:1:10 and had a polymer-drug ratio of 11.0 ; the $\mathrm{EE} \%$ was $90.14 \%$, and $5 \mathrm{mg} / \mathrm{mL}$ of the AmB solubilized, whereas the free AmB exhibited poor solubility in water $(<1 \mu \mathrm{g} / \mathrm{mL})$. In addition, the effect of lecithin on particle size was evaluated, and we determined that, in the mixed polymeric micelle system, lecithin and DSPE-PEG2K can be used to achieve stability and a desirable particle size.

Regarding PKs, the absorption of Ambicelles was 2.18fold higher than that of the Fungizone ${ }^{\circledR}$ after intravenous administration, possibly because of micellar formation. Ambicelles encapsulated the AmB effectively and released it slowly, resulting in a greater AUC, which typically represents a longer exposure to AmB. Previous studies have determined that continuous infusion of $\mathrm{AmB}$ over 24 hours is more easily tolerated than a standard 2-4-hour infusion. ${ }^{45-48}$ Thus, slow and sustained monomeric AmB release is beneficial and reduces the possibility of toxicity. By contrast, for oral administration, the absolute BA of Ambicelles was 1.50-fold greater than that of Fungizone ${ }^{\circledR}$. The increased BA following oral administration was less apparent than that after intravenous administration. The results revealed that Ambicelles was stable in SGF and SIF and, thus, no degradation should occur in the GI tract. Although the Ambicelles increased the 
AmB solubility from $<1 \mu \mathrm{g} / \mathrm{mL}$ to $5 \mathrm{mg} / \mathrm{mL}, \mathrm{AmB}$ is classified as BCS (Biological Classification System) Class 4 (low solubility and low permeation); the poor oral BA may result from the low permeation of AmB in the GI tract.

According to the in vitro cytotoxicity study, cell viability was higher when cells were treated with Ambicelles, indicating that Ambicelles encapsulated the AmB effectively and prevented the AmB from directly touching the cell; thus, Ambicelles is a safe formulation. When HT29 cells were pretreated with $50 \mu \mathrm{g} / \mathrm{mL}$ of TCEE followed by Fungizone ${ }^{\circledR}$ or Ambicelles, the $\mathrm{IC}_{50}$ of Ambicelles was lower than that for Fungizone ${ }^{\circledR}$. Because the TCEE pretreatment enhanced the sensitivity of the cancer cell membranes to $\mathrm{AmB}$ and increased cell death, pretreating the cells with TCEE before administering Ambicelles effectively inhibited the growth of HT29 cells and produced a synergistic anticancer effect.

\section{Conclusion}

In this study, we developed a self-assembling lecithin-based mixed polymeric micelle for encapsulating AmB by using a thin film method. The optimal formulation, Ambicelles, comprised AmB:lecithin:DSPE-PEG2K =1:1:10; the lecithin reduced the micelle size and the DSPE-PEG2K stabilized the micelles that were not in the TPGS, Kolliphor ${ }^{\circledR}$, and Pluronic ${ }^{\circledR}$ series. The particle size, polydispersion index, $\mathrm{EE} \%$, and DL\% were $187.20 \pm 10.55 \mathrm{~nm}, 0.51 \pm 0.017,90.14 \%$, and $7.51 \%$, respectively, and the solubility was substantially enhanced. The BA of Ambicelles administered intravenously and orally was higher than those of Fungizone ${ }^{\circledR}$ because the micellar formulation enabled the slow and sustained release of monomeric AmB. Regarding the in vitro viability, Ambicelles was less cytotoxic than was free AmB or Fungizone ${ }^{\circledR}$. After HT29 colon cancer cells were pretreated with TCEE, the $\mathrm{IC}_{50}$ of Ambicelles was lower than that of the AmB solution or Fungizone ${ }^{\circledR}$, indicating that Ambicelles produced a higher synergistic anticancer effect.

\section{Disclosure}

The authors report no conflicts of interest in this work.

\section{References}

1. Zuco V, Supino R, Righetti SC, et al. Selective cytotoxicity of betulinic acid on tumor cell lines, but not on normal cells. Cancer Lett. 2002;175(1):17-25.

2. Brajtburg J, Powderly WG, Kobayashi GS, Medoff G. Amphotericin B: delivery systems. Antimicrob Agents Chemother. 1990;34(3): 381-384.

3. Lemke A, Kiderlen AF, Kayser O. Amphotericin B. Appl Microbiol Biotechnol. 2005;68(2):151-162.
4. Charbonneau C, Fournier I, Dufresne S, Barwicz J, Tancrède P. The interactions of amphotericin B with various sterols in relation to its possible use in anticancer therapy. Biophys Chem. 2001;91(2): 125-133.

5. Chen LY, Sheu MT, Liu DZ, et al. Pretreatment with an ethanolic extract of Taiwanofungua camphoratus (Antrodia camphorata) enhances the cytotoxic effects of amphotericin B. J Agric Food Chem. 2011;59(20): 11255-11263.

6. Girois SB, Chapuis F, Decullier E, Revol BGP. Erratum: Adverse effects of antifungal therapies in invasive fungal infections: review and meta-analysis. Eur J Clin Microbiol Infect Dis. 2006;25(2):138-149.

7. Gallis HA, Drew RH, Pickard WW. Amphotericin B: 30 years of clinical experience. Rev Infect Dis. 1990;12(2):308-329.

8. Vandermeulen G, Rouxhet L, Arien A, Brewster ME, Preat V. Encapsulation of amphotericin B in poly(ethylene glycol)-block-poly (epsilon-caprolactone-co-trimethylenecarbonate) polymeric micelles. Int J Pharm. 2006;309(1-2):234-240.

9. Barwicz J, Christian S, Gruda I. Effects of the aggregation state of amphotericin B on its toxicity to mice. Antimicrob Agents Chemother. 1992; 36(10):2310-2315.

10. Legrand P, Romero EA, Cohen BE, Bolard J. Effects of aggregation and solvent on the toxicity of amphotericin B to human erythrocytes. Antimicrob Agents Chemother. 1992;36(11):2518-2522.

11. Hiemenz JW, Walsh TJ. Lipid formulations of amphotericin B: recent progress and future directions. Clin Infect Dis. 1996;22(Suppl 2); S133-S144.

12. Wong-Beringer A, Jacobs RA, Guglielmo BJ. Lipid formulations of amphotericin B: clinical efficacy and toxicities. Clin Infect Dis. 1998; 27(3):603-618.

13. Gaucher G, Dufresne MH, Sant VP, Kang N, Maysinger D, Leroux JC. Block copolymer micelles: preparation, characterization and application in drug delivery. J Control Release. 2005;109(1-3):169-188.

14. Torchilin VP. Structure and design of polymeric surfactant-based drug delivery systems. J Control Release. 2001;73(2-3):137-172.

15. Gong J, Chen M, Zheng Y, Wang S, Wang Y. Polymeric micelles drug delivery system in oncology. $J$ Control Release. 2012;159(3): 312-323.

16. Lu Y, Park K. Polymeric micelles and alternative nanonized delivery vehicles for poorly soluble drugs. Int J Pharm. 2013;453(1):198-214.

17. Jones M, Leroux J. Polymeric micelles - a new generation of colloidal drug carriers. Eur J Pharm Biopharm. 1999;48(2):101-111.

18. Yokoyama M. Polymeric micelles as a new drug carrier system and their required considerations for clinical trials. Expert Opin Drug Deliv. 2010;7(2):145-158.

19. Krishnadas A, Rubinstein I, Onyuksel H. Sterically stabilized phospholipid mixed micelles: in vitro evaluation as a novel carrier for water-insoluble drugs. Pharm Res. 2003;20(2):297-302.

20. Jin X, Zhang Z-h, Sun E, et al. Preparation of icariside II-phospholipid complex and its absorption across Caco-2 cell monolayers. Pharmazie. 2012;67(4):293-298.

21. Wei Z, Hao J, Yuan S, et al. Paclitaxel-loaded Pluronic P123/F127 mixed polymeric micelles: formulation, optimization and in vitro characterization. Int J Pharm. 2009;376(1-2):176-185.

22. Zhao L, Shi Y, Zou S, Sun M, Lil L, Zhail G. Formulation and in vitro evaluation of quercetin loaded polymeric micelles composed of pluronic P123 and D-a-tocopheryl polyethylene glycol succinate. J Biomed Nanotechnol. 2011;7(3):358-365.

23. Kabanov AV, Batrakova EV, Alakhov VY. Pluronic (R) block copolymers as novel polymer therapeutics for drug and gene delivery. $J$ Control Release. 2002;82(2-3):189-212.

24. Risovic V, Boyd M, Choo E, Wasan KM. Effects of lipid-based oral formulations on plasma and tissue amphotericin B concentrations and renal toxicity in male rats. Antimicrob Agents Chemother. 2003; 47(10):3339-3342.

25. Dangi JS, Vyas SP, Dixit VK. Effect of various lipid-bile salt mixed micelles on the intestinal absorption of amphotericin-B in rat. Drug Dev Ind Pharm. 1998;24(7):631-635. 
26. Lance MR, Washington C, Davis SS. Structure and toxicity of amphotericin B/triglyceride emulsion formulations. J Antimicrob Chemother. 1995;36(1):119-128.

27. Souza LC, Saldiva PHN, Campa A. Lipid emulsion reduces subacute toxicity of amphotericin B: a histopathological study. Exp Toxicol Pathol. 2000;52(2):169-175.

28. Vakil R, Kwon GS. PEG-phospholipid micelles for the delivery of amphotericin B. J Control Release. 2005;101(1-3):386-389.

29. Tan Q, Liu W, Guo C, Zhai G. Preparation and evaluation of quercetinloaded lecithin-chitosan nanoparticles for topical delivery. Int J Nanomedicine. 2011;6:1621-1630.

30. Li H, Zhao X, Ma Y, Zhai G, Li L, Lou H. Enhancement of gastrointestinal absorption of quercetin by solid lipid nanoparticles. J Control Release. 2009;133(3):238-244.

31. Yanyu X, Yunmei S, Zhipeng C, Qineng P. The preparation of silybinphospholipid complex and the study on its pharmacokinetics in rats. Int J Pharm. 2006;307(1):77-82.

32. Zhang XC, Jackson JK, Burt HM. Development of amphiphilic diblock copolymers as micellar carriers of taxol. Int J Pharmaceutics. 1996;132(1-2):195-206.

33. Italia JL, Singh D, Kumar MNR. High-performance liquid chromatographic analysis of amphotericin B in rat plasma using alpha-naphthol as an internal standard. Anal Chim Acta. 2009;634(1):110-114.

34. Lavasanifar A, Samuel J, Kwon GS. Micelles self-assembled from poly(ethylene oxide)-block-poly(N-hexyl stearate L-aspartamide) by a solvent evaporation method: effect on the solubilization and haemolytic activity of amphotericin B. J Control Release. 2001; 77(1-2):155-160.

35. Allemann E, Gurny R, Doelker E. Drug-loaded nanoparticles Preparation methods and drug targeting issues. Eur J Pharm Biopharm. 1993;39(5):173-191.

36. Zhang ZP, Tan SW, Feng SS. Vitamin E TPGS as a molecular biomaterial for drug delivery. Biomaterials. 2012;33(19):4889-4906.

37. Deepa G, Ashwanikumar N, Pillai JJ, Kumar GSV. Polymer nanoparticles - a novel strategy for administration of Paclitaxel in cancer chemotherapy. Curr Med Chem. 2012;19(36):6207-6213.
38. Wang R, Xiao R, Zeng Z, Xu L, Wang J. Application of poly(ethylene glycol)-distearoylphosphatidylethanolamine (PEG-DSPE) block copolymers and their derivatives as nanomaterials in drug delivery. Intl $J$ Nanomedicine. 2012;7:4185-4198.

39. Remsberg CM, Zhao Y, Takemoto JK, Bertram RM, Davies NM, Forrest ML. Pharmacokinetic evaluation of a DSPE-PEG2000 micellar formulation of ridaforolimus in rat. Pharmaceutics. 2012;5(1):81-93.

40. Li SD, Huang L. Stealth nanoparticles: high density but sheddable PEG is a key for tumor targeting. J Control Release. 2010;145(3):178-181.

41. Allen TM, Hansen C, Martin F, Redemann C, Yau-Young A. Liposomes containing synthetic lipid derivatives of poly(ethylene glycol) show prolonged circulation half-lives in vivo. Biochim Biophys Acta. 1991;1066(1):29-36.

42. Ashok B, Arleth L, Hjelm RP, Rubinstein I, Önyüksel H. In vitro characterization of PEGylated phospholipid micelles for improved drug solubilization: effects of PEG chain length and PC incorporation. J Pharm Sci. 2004;93(10):2476-2487.

43. Gabizon AA, Barenholz Y, Bialer M. Prolongation of the circulation time of doxorubicin encapsulated in liposomes containing a polyethylene glycol-derivatized phospholipid: pharmacokinetic studies in rodents and dogs. Pharm Res. 1993;10(5):703-708.

44. Lukyanov AN, Torchilin VP. Micelles from lipid derivatives of watersoluble polymers as delivery systems for poorly soluble drugs. $A d v$ Drug Deliv Rev. 2004;56(9):1273-1289.

45. Imhof A, Walter RB, Schaffner A. Continuous infusion of escalated doses of amphotericin B deoxycholate: an open-label observational study. Clin Infect Dis. 2003;36(8):943-951.

46. Eriksson U, Seifert B, Schaffner A. Comparison of effects of amphotericin B deoxycholate infused over 4 or 24 hours: randomised controlled trial. BMJ. 2001;322(7286):579-582.

47. Peleg AY, Woods ML. Continuous and $4 \mathrm{~h}$ infusion of amphotericin B: a comparative study involving high-risk haematology patients. $J$ Antimicrob Chemother. 2004;54(4):803-808.

48. Hiemenz JW. Amphotericin B deoxycholate administered by continuous infusion: dose the dosage make a difference? Clin Infect Dis. 2003;36(8):952-953.
International Journal of Nanomedicine

\section{Publish your work in this journal}

The International Journal of Nanomedicine is an international, peerreviewed journal focusing on the application of nanotechnology in diagnostics, therapeutics, and drug delivery systems throughout the biomedical field. This journal is indexed on PubMed Central, MedLine, CAS, SciSearch $®$, Current Contents ${ }^{\circledR} /$ Clinical Medicine,

\section{Dovepress}

Journal Citation Reports/Science Edition, EMBase, Scopus and the Elsevier Bibliographic databases. The manuscript management system is completely online and includes a very quick and fair peer-review system, which is all easy to use. Visit http://www.dovepress.com/ testimonials.php to read real quotes from published authors. 